\title{
Midterm results of surgical intervention for congenital heart disease in adults: An Italian multicenter study
}

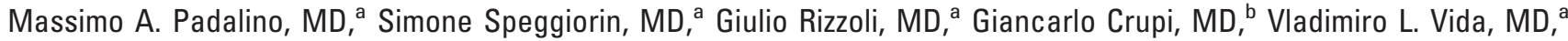 \\ Massimo Bernabei, MD, ${ }^{\mathrm{c}}$ Gaetano Gargiulo, MD, ${ }^{\mathrm{d}}$ Alessandro Giamberti, MD, ${ }^{\mathrm{e}}$ Francesco Santoro, MD, ${ }^{f}$ \\ Carlo Vosa, MD, ${ }^{\mathrm{g}}$ Giuseppe Pacileo, MD, ${ }^{\mathrm{g}}$ Raffaele Calabrò, MD, ${ }^{\mathrm{g}}$ Luciano Daliento, MD, ${ }^{\mathrm{h}}$ and Giovanni Stellin, MD ${ }^{\mathrm{a}}$
}

Earn CME credits at http://cme.ctsnetjournals.org

Supplemental material is available online.
From the Pediatric and Congenital Cardiac Surgery Unit, ${ }^{a}$ Centro Gallucci, University of Padua Medical School, Padua, Italy; the Department of Cardiovascular Surgery, ${ }^{\mathrm{b}}$ Ospedali Riuniti di Bergamo, Bergamo, Italy; the Department of Pediatric Cardiology, Ospedale G. Pasquinucci CREAS-CNR, Massa, Italy; the Department of Pediatric Cardiac Surgery, ${ }^{\mathrm{d}}$ Azienda Ospedaliera S. Orsola-Malpighi, Bologna, Italy; the Department of Cardiac Surgery, ${ }^{\text {I Istituto Poli- }}$ clinico San Donato, Milano, Italy; the Department of Cardiac Surgery, ${ }^{f}$ Ospedale Niguarda Cà Granda, Milano, Italy; Pediatric Cardiology and Cardiac Surgery, ${ }^{\mathrm{g}}$ Second University, A.O. Monaldi, Naples, Italy; and the Department of Cardiology, ${ }^{\text {h }}$ Centro Gallucci, University of Padua Medical School, Padua, Italy.

Read at the Eighty-sixth Annual Meeting of The American Association for Thoracic Surgery, Philadelphia, Pa, April 29-May 3, 2006.

Received for publication June 28, 2006; revisions received Jan 13, 2007; accepted for publication Jan 23, 2007.

Address for reprints: Giovanni Stellin, MD, Pediatric and Congenital Cardiac Surgery Unit, Centro Gallucci, Department of Cardiac, Thoracic and Vascular Sciences, University of Padova Medical School, Via Giustiniani 2 - 35128 Padova, Italy (E-mail: giovanni.stellin@unipd.it).

J Thorac Cardiovasc Surg 2007;134:106-13 $0022-5223 / \$ 32.00$

Copyright $\odot 2007$ by The American Association for Thoracic Surgery

doi:10.1016/j.jtcvs.2007.01.080
Objective: We have analyzed, in a clinical multicenter study, the effect of cardiac surgery in adults with congenital heart disease in Italy.

Methods: We collected clinical data from 856 patients aged 19 years or older who underwent surgical intervention from January 1, 2000, to December 31, 2004. Patients were divided into 3 surgical groups: group 1, palliation (3.1\%); group 2, repair (69.7\%); and group 3, reoperation (27.4\%).

Results: Preoperatively, 34.6\% of patients were in New York Heart Association class I, $48.4 \%$ were in class II, $14.2 \%$ were in class III, and $2.8 \%$ were in class IV. Sinus rhythm was present in $83 \%$. There were 1179 procedures performed in 856 patients (1.37 procedures per patient), with a hospital mortality of $3.1 \%$. Overall mean intensive care unit stay was 2.3 days (range, 1-102 days). Major complications were reported in 247 (28.8\%) patients, and postoperative arrhythmias were the most frequent. At a mean follow-up of 22 months (range, 1 month-5.5 years; completeness, $87 \%)$, late death occurred in $5(0.5 \%)$ patients. New York Heart Association class was I in $79.3 \%$, II in $17.6 \%$, and III in $2.9 \%$, and only $1(0.11 \%)$ patient was in class IV. Overall survival estimates are $82.6 \%, 98.9 \%$, and $91.8 \%$ at 5 years for groups 1,2 , and 3, respectively. Freedom from adverse events at 5 years is $91 \%$ for acyanotic patients versus $63.9 \%$ for preoperative cyanotic patients $(P<$ $.0001)$.

Conclusions: Surgical intervention for congenital heart disease in adults is a safe and low-risk treatment. However, patients presenting with preoperative cyanosis show a higher incidence of late adverse events and complications.

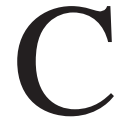
ongenital heart malformations are currently treated in pediatric patients. However, adults and adolescents with congenital heart disease are becoming an important entity because recent improved diagnostic and therapeutic tools allow the majority of newborns with congenital heart disease (CHD) to survive to adulthood. ${ }^{1}$ Currently, adults with CHD in Italy are calculated to number approximately $80,000 .^{2}$ Thus, the effect of such a huge population on the medical community is expected to be relevant.

For this reason, we have designed a multicenter study involving 7 major Italian cardiac centers, to evaluate the early and midterm outcomes of cardiac surgery in this particular group in our country.

\section{Materials and Methods}

All major congenital cardiac centers in Italy (12) were invited to be part of this study in a 5-year time frame under the supervision of the Italian Society of Cardiology. Seven centers joined the study by sending complete data and respecting requirements as indicated in a preset database. The database was designed based on demographic, pathologic, surgical, and postoperative data, as requested in the EACTS Congenital Database (www.eactscongenitaldb.org). There is no age 


\author{
Abbreviations and Acronyms \\ ASD = atrial septal defect \\ $\mathrm{CHD}=$ congenital heart disease \\ HR = hazard ratio \\ NYHA $=$ New York Heart Association
}

restriction in this database as far as the data collection is concerned. All centers are medium-high surgical volume centers, with the number of cases ranging between 200 and 450 cases per year. All the participating centers are tertiary level national centers. Five of the 7 centers have a cardiac transplantation program, and 2 centers are authorized for heart-lung transplantation. Data were collected by one of the authors in every center, and all material was validated by the coordinating authors (M.A.P. and G.S., Padua).

Eight hundred fifty-six patients were enrolled who underwent operations for a variety of CHDs between January 1, 2000, and December 31, 2004. The male/female ratio was 1.13 (455 men [53.2\%] and 401 women [46.8\%]). Age ranged between 18 and 80 years (mean, 37.2 years; median, 34.2 years). Diagnoses, procedures, extracardiac anomalies, preoperative risk factors, and postoperative complications were classified according to the EACTS Congenital Database classification, as described elsewhere. ${ }^{3}$ Diagnoses were divided into "anatomic" (as the basic heart malformation) and "leading to surgical intervention" (as the cause for operation, regardless of the basic anatomy) categories (Table E1).

Surgical procedures (intended as a surgical procedure for a single major congenital cardiac lesion; more than one surgical procedure might be associated in the same operation in the same patient with a complex congenital cardiac lesion) were arbitrarily divided into 3 groups: group 1, palliative procedures, defined as any operation performed to improve the patient's clinical status without restoring normal anatomy or physiology (Table 1); group 2 , repair procedures, defined as any operation designed to achieve an anatomic or physiologic correction resulting in a separation of the pulmonary from the systemic circulation (we have included in this group the Fontan-type repair and the one-and-a-half ventricle repair; Table 2); and group 3, reoperation, defined as any cardiac surgical procedure after either physiologic or anatomic repair (Table 3).

Follow-up was based on clinical data derived from the Congenital Heart Disease in Adults database followed by each center, which considers onset of adverse events listed as follows: late

\section{TABLE 1. Palliative procedures}

\begin{tabular}{lr}
\hline Palliative procedure & $\%$ \\
\hline Bidirectional cavopulmonary anastomosis & 20.7 \\
$\quad$ (Glenn procedure) & 13.8 \\
Pulmonary artery banding & 10.3 \\
Surgical ablation & 10.3 \\
Blalock-Taussig shunt & 3.4 \\
Systemic-to-pulmonary artery shunt & \\
$\quad$ ligation and takedown & 41.4 \\
Other procedures (miscellaneous) &
\end{tabular}

\section{TABLE 2. Repair procedures}

\begin{tabular}{lr}
\hline Surgical procedure & $\%$ \\
\hline Atrial septal defect closure & 36.1 \\
Partial anomalous pulmonary venous & 7.2 \\
$\quad$ connection repair & \\
Ventricular septal defect closure & 5.4 \\
Ross operation & 5.3 \\
Atrioventricular septal defect-partial & 5.1 \\
type repair & \\
Tricuspid valve plasty & 4.8 \\
Aortic valve replacement & 3.7 \\
Subaortic stenosis resection & 3.2 \\
Aortic repair & 2.4 \\
Mitral valve plasty & 2.2 \\
Surgical ablation & 2.2 \\
Right ventricular outflow tract & 2.1 \\
procedure & \\
Aortic coarctation repair & 2 \\
Tetralogy of Fallot repair & 1 \\
Mitral valve replacement & 0.7 \\
Other procedures & 16.6 \\
\hline
\end{tabular}

cardiac death, late noncardiac death, reoperation, interventional cardiology procedure, and "other."

Survival estimates for all patients were analyzed with the Kaplan-Meier method applied to the main cardiac lesion (atrial septal defect [ASD], right heart lesion, left heart lesion, and single ventricle) and to the main lesion stratified in the 3 different operative categories (palliation, repair, and reoperation). The effect of preoperative functional New York Heart Association (NYHA) class III and IV, with or without associated cyanosis, was similarly evaluated. Statistically significant incremental (hazard ratio [HR], $>1.0)$ or decremental $(\mathrm{HR},<1.0)$ risk factors were identified by means of a forward stepwise $(P$ to enter $=.05, P$ to remain $=.2)$

\section{TABLE 3. Reoperations}

\begin{tabular}{lc}
\hline Reoperation & $\%$ \\
\hline Conduit reoperation & 9.9 \\
Aortic valve replacement & 7.7 \\
Pulmonary valve replacement & 6.8 \\
Ventricular septal defect & 4.6 \\
Tricuspid valve plasty & 4.3 \\
Right ventricular outflow tract procedure & 4 \\
Subaortic stenosis resection & 3.7 \\
Aortic aneurysm repair & 3.7 \\
Atrial septal defect closure & 3.4 \\
Mitral valve replacement & 3.1 \\
Heart transplantation & 2.5 \\
Pulmonary artery plasty & 2.2 \\
Right ventricle-pulmonary artery conduit & 2.2 \\
Aortic coarctation repair & 1.9 \\
Ross procedure & 1.5 \\
Mitral valve plasty & 1.5 \\
Other & 25.3 \\
\hline
\end{tabular}


Cox analysis of operative categories of surgical intervention, pathologies, and preoperative risk factors.

\section{Results}

Noninvasive preoperative diagnosis by means of 2-dimensional and Doppler echocardiography (associated or not with other noninvasive techniques) was possible in 530 $(61.9 \%)$ patients. Cardiac catheterization in association with noninvasive techniques was used in 273 (31.8\%) patients, in $39(4.5 \%)$ patients diagnosis was made by means of cardiac catheterization only, and magnetic resonance imaging was sufficient in $13(1.5 \%)$ patients. No data were available for 1 patient.

According to the preoperative clinical and instrumental evaluation, 294 (34.6\%) patients were classified in NYHA functional class I, $412(48.4 \%)$ in class II, $120(14.2 \%)$ in class III, and $24(2.8 \%)$ in class IV $(2.8 \%)$. No data were available for 7 patients.

Preoperative electrocardiography showed sinus rhythm in $83 \%$ of patients. Major arrhythmias included atrial fibrillation in $55(6.4 \%)$ patients, supraventricular tachyarrhythmias in $13(1.5 \%)$ patients, complete atrioventricular block in 10 patients $(1.1 \%)$, and atrial flutter in 6 patients $(0.7 \%)$. No data were available in 75 patients $(8.8 \%)$.

Associated extracardiac anomalies were present in 40 patients and included Marfan syndrome in 19 (2.3\%), Down syndrome in $12(1.4 \%)$, Williams-Beuren syndrome in 3 $(0.3 \%)$, and Turner syndrome in 1 . Other nonsignificant chromosomal anomalies were found in 4 patients.

We collected 1196 "anatomic diagnoses" in 856 patients. Table E1 shows diagnoses of basic heart malformation and diagnoses "leading to surgical intervention."

There were 1179 surgical procedures performed in 856 patients in 7 centers (mean, 122.3 procedures per center; range, 34-334 procedures). Among these, there were 30 palliative procedures (group 1) performed in 18 patients (2.4\%, Table 1), 742 repair procedures (group 2) in 628 patients $(69.5 \%$, Table 2), and 322 reoperations (Group 3 ) in 210 patients $(27.4 \%$, Table 3$)$. Types of procedures are shown in Tables 1 through 3 .

Twenty-seven patients died within 30 days or before hospital discharge (early overall mortality, 3.1\%). The most common causes of death were low cardiac output syndrome in $13(1.5 \%)$ patients, bleeding in 3 patients, and sepsis in 2 patients. The palliation group presented with the highest early mortality $(16.6 \%)$ when compared with group 2 $(1.3 \%)$ and group $3(7.6 \%)$. Main causes of death are listed in Table E2.

Mean intensive care unit stay was 2.3 days (range, 1-102 days): 5.2 days in group 1, 1.8 days in group 2 , and 3.5 days in group 3. Postoperative complications were reported in 247 (28.8\%) patients. The most common complications included postoperative arrhythmias (64 events), low cardiac output syndrome (28 events), bleeding requiring reoperation
(24 events), pleural effusion requiring drainage (19 events), postoperative mechanical ventilation for more than 7 days (17 events), and pneumothorax (10 events). Postoperative arrhythmia and bleeding were the most common complications in group 2, whereas in groups 1 and 3 low cardiac output syndrome complicated the postoperative course more commonly (Table E2). Seven patients, the majority of whom were younger than 30 years, were started unsuccessfully on mechanical circulatory support devices.

Cardiac rhythm at the moment of discharge from the hospital showed $90.5 \%$ of patients with sinus rhythm by means of electrocardiography, whereas $2.5 \%$ showed atrial fibrillation, $0.8 \%$ (7 patients) showed complete atrioventricular block, and 2 patients showed atrial flutter. This compares favorably with preoperative electrocardiographic data; however, these differences were not statistically significant. In addition, CAVB incidence is reduced because 3 of the patients affected died at the time of the operation (Table E3).

\section{Follow-up}

The follow-up period ranged from 1 month to 5.2 years (mean, 21.8 months; median, 18.9 months). Follow-up completeness was $87 \%$ (744/856 patients).

Overall, there were 48 adverse events among survivors, with arrhythmias and chest effusions (pleural or pericardial) being the most common. Late cardiac death occurred in 4 $(0.46 \%)$ patients; in one additional case death was noncardiac related. Reoperation was necessary in $9(1 \%)$ patients, consisting mainly of valve replacement ( 2 patients) and pacemaker implantation ( 2 patients); heart transplantation was performed in 1 patient. Interventional cardiology procedures were done in $5(0.5 \%)$ patients and were mainly antiarrhythmia procedures (3 patients). All data are exposed in Table E4.

At latest follow-up, $79.3 \%$ of the patients are in NYHA class I, $17.6 \%$ are in class II, $2.9 \%$ are in class III, and only 1 patient is in class IV (corrected transposition of the great arteries after pulmonary artery banding and mitral valve plasty). The ability index is estimated as grade I in $82.4 \%$, grade II in $13.7 \%$, and grade III in $2.3 \%$. None were found to be in ability index grade IV. Data were not available in $1.6 \%$ of patients.

\section{Statistical Analysis}

Overall survival at 5 years for all procedures is $96 \%$. Survival curves according to Kaplan-Meier analysis are shown in the following figures.

Survival estimate is $82.6 \%$ at 4 years for palliation procedures, $98.9 \%$ for repair, and $91.8 \%$ for reoperation at 5 years $(P<.0001$, Figure 1$)$.

Survival estimate for patients in preoperative NYHA class IV associated or not with cyanosis is significantly 


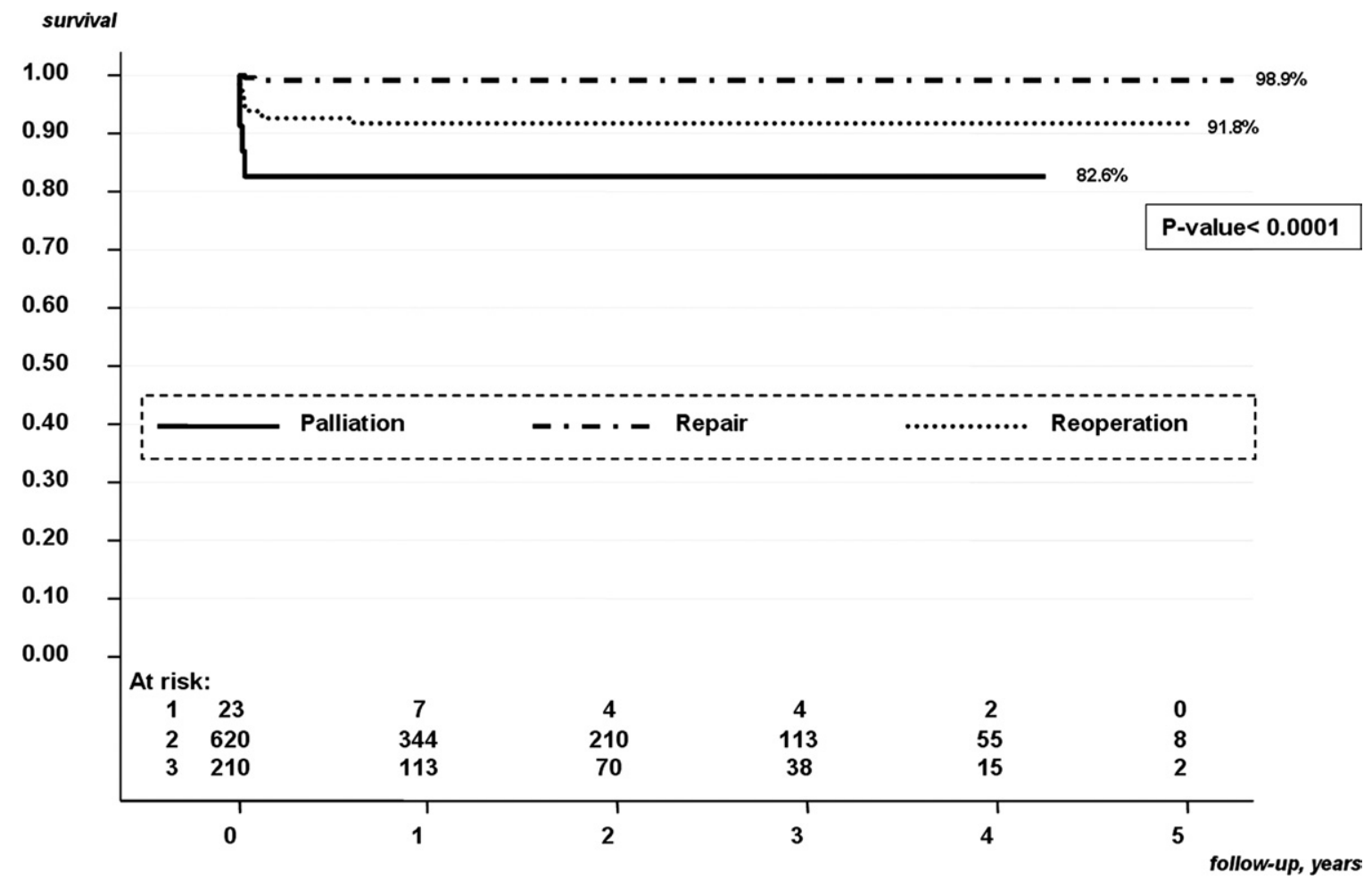

Figure 1. Kaplan-Meier survival estimates by surgical category.

lower versus that seen in other patients $(70 \%$ and $92.3 \%$ vs 97.1\%, $P<.0001$, Figure E1).

Survival estimate for patients in preoperative NYHA class III is significantly lower versus that seen in other patients (97.1\% vs $90.4 \%, P=.012$, Figure E2).

Survival estimate is $99.7 \%$ at 5 years for patients with ASD and $93.5 \%$ at 5 years for all other pathologies $(P<$ .0001, Figure E3).

Survival estimate for patients with single-ventricle physiology is $75 \%$ versus $97 \%$ for those without single-ventricle physiology ( $P<.0001$, Figure E4); however, there is no significant difference for these patients when considered by surgical category $(P=.24$, Figure E5).

Survival estimate for patients with a right heart lesion is $92.8 \%$ versus $97.2 \%$ for patients without $(P=.023$, Figure E6); in addition, survival in patients with a right heart lesion by category is $77.8 \%$ for palliation, $95.9 \%$ for repair, and 91.2\% for reoperation ( $P=.0292$, Figure E7).

Survival estimate for patients with a left heart lesion is $98.9 \%$ versus $95.3 \%$ for patients without a lesion $(P=.05$, Figure E8); however, there is no significant difference for these patients when considered by category $(P=.0884)$, Figure E9.

Survival estimate is $97.4 \%$ at 5 years for preoperative acyanotic patients and $88.8 \%$ at 5 years for preoperative cyanotic patients $(P<.0001$ (Figure 2$)$.
Overall freedom from adverse events is $88 \%$ at 5 years (Figure 3).

Freedom from any kind of adverse event is $91 \%$ for noncyanotic patients versus $63.9 \%$ at 5 years $(P<.0001$, Figure E10).

Multivariate Cox analysis identifies the following parameters among the most powerful incremental risk factors: (1) preoperative NYHA class IV in cyanotic patients (HR, 8.6; $P=.001)$; (2) preoperative NYHA class III (HR, 2.7; $P=$ $.023)$; (3) single-ventricle physiology as a preoperative diagnosis (HR, 2.6; $P=.032$ ); and (4) reoperation (HR, 2.3; $P=.029)$.

According to multivariate Cox analysis, the most powerful decremental risk factors are (1) ASD diagnosis (HR, $0.08 ; P=.0018$ ) and (2) left heart lesion diagnosis (HR, $0.16 ; P=.014)$.

\section{Discussion}

Very few patients with CHD can survive to adult age without surgical intervention. Since the late 1960s, the success of cardiac medical and surgical therapy has drastically modified the natural history of almost all CHDs. This improvement has selected a growing number of newborns and infants who have survived through adolescence until adulthood. These adults constitute a new medical community that is commonly called Grown-up Congenital Heart 


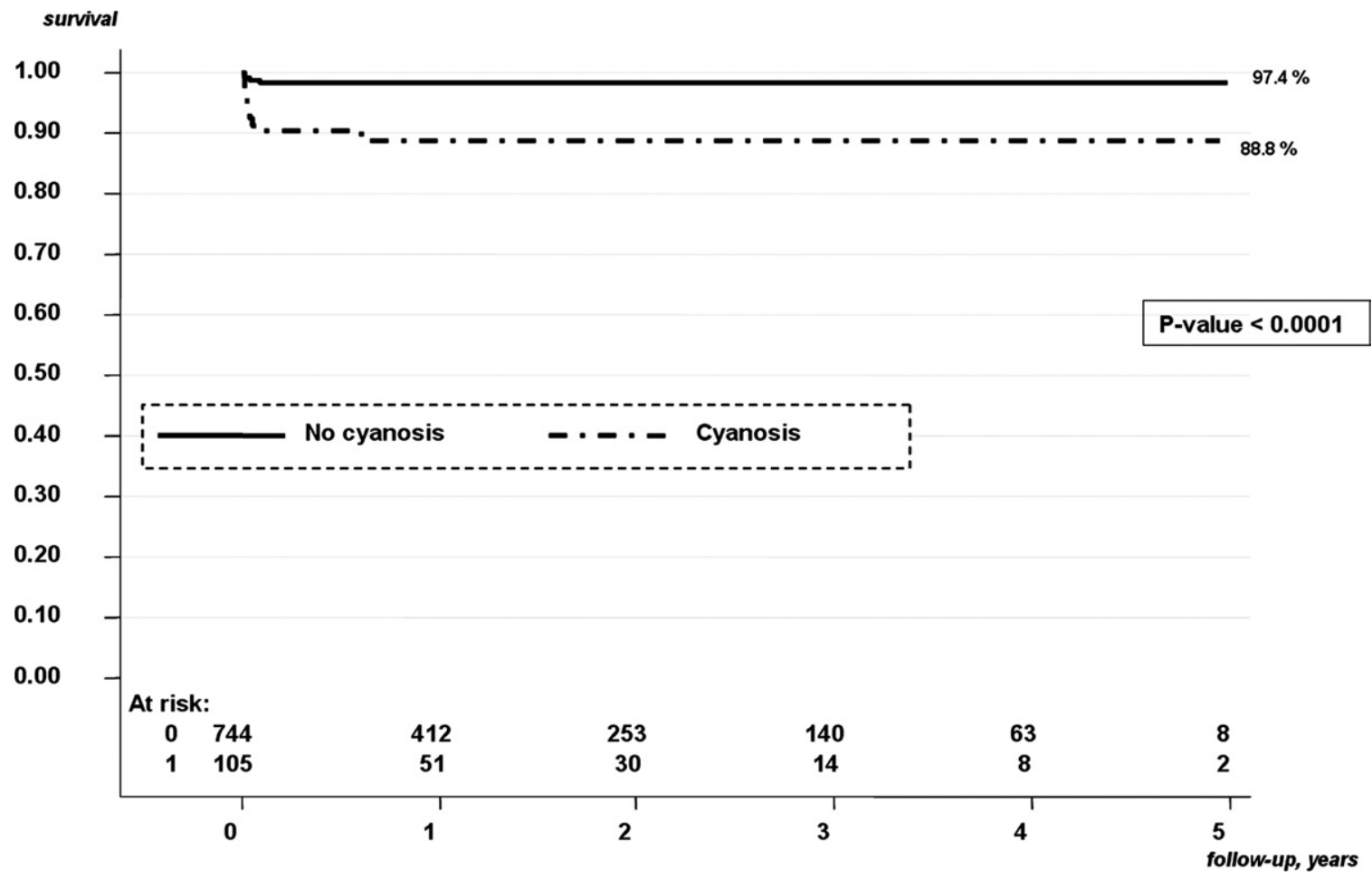

Figure 2. Kaplan-Meir survival estimates by preoperative cyanosis.

disease $^{4}$ or adult CHD. ${ }^{5}$ In the year 2000 , the number of adult patients with CHD was calculated to be equal to the number of pediatric patients, and it is expected that 20 years from now, the number of adult patients with CHD will exceed those in pediatric care by a considerable margin. ${ }^{1,6}$ Based on an English study model, ${ }^{7}$ it is expected that in Italy there are currently 60,000 to 100,000 adult patients with CHD requiring follow-up. ${ }^{2}$

The effect of such a peculiar group of patients on the medical community is relevant. This population of adults has special needs and peculiar problems. ${ }^{1,2,4}$ As outlined by Warnes, ${ }^{9}$ despite great advances in diagnosis and therapy occurring in the last decades, many intracardiac repairs and circulations might still not function normally. Residual problems are common, and they might need a lifelong follow-up, with appropriate treatment and care, either medical or surgical.

Somerville ${ }^{4}$ estimates that almost $20 \%$ of admissions to a so-called Grown-up Congenital Heart disease unit are for surgical indications. Adult patients are usually referred for surgical intervention because of an increase in symptoms that is not controllable with medical therapy. ${ }^{4}$ In our experience, before surgical intervention, the majority of patients have been in NYHA class I or II, and surgical intervention was dictated more by the existing diagnosis than symptoms, with the aim of restoring the normal circulation and modifying the natural history of CHD.

The analysis of data collected in our multicenter study indicates that cardiac surgery in patients with adult CHD has been characterized by a relatively low overall operative mortality $(3.1 \%)$. This is comparable with our previous reported European experience of $2.4 \%^{3}$ and considerably lower than $6.3 \%$, as reported by Srinathan and colleagues. ${ }^{10}$ It is of note, however, that we are analyzing patients who, frequently, were preoperatively in good clinical condition (NYHA class I or II in the majority), and ASD was undoubtedly a very common "leading to surgical intervention" diagnosis. This has certainly influenced our good early outcome. For this reason, in our analysis we have extrapolated the survival for patients with a diagnosis other than ASD, and we have found that in this selected group, mortality is still inferior to $6 \%$. This might support the common feeling that precocious diagnosis and surgical treatment before irreversible cardiac decompensation and onset of severe symptoms is a rational strategy to improve results.

In addition, our statistical analysis shows an estimated cumulative survival of $96 \%$ at 5 years; when considered by category, it is higher for complete repair (98.9\%) compared with reoperations $(91.8 \%)$ and palliation $(82.6 \%)$. Thus despite repair of congenital heart defects being performed 


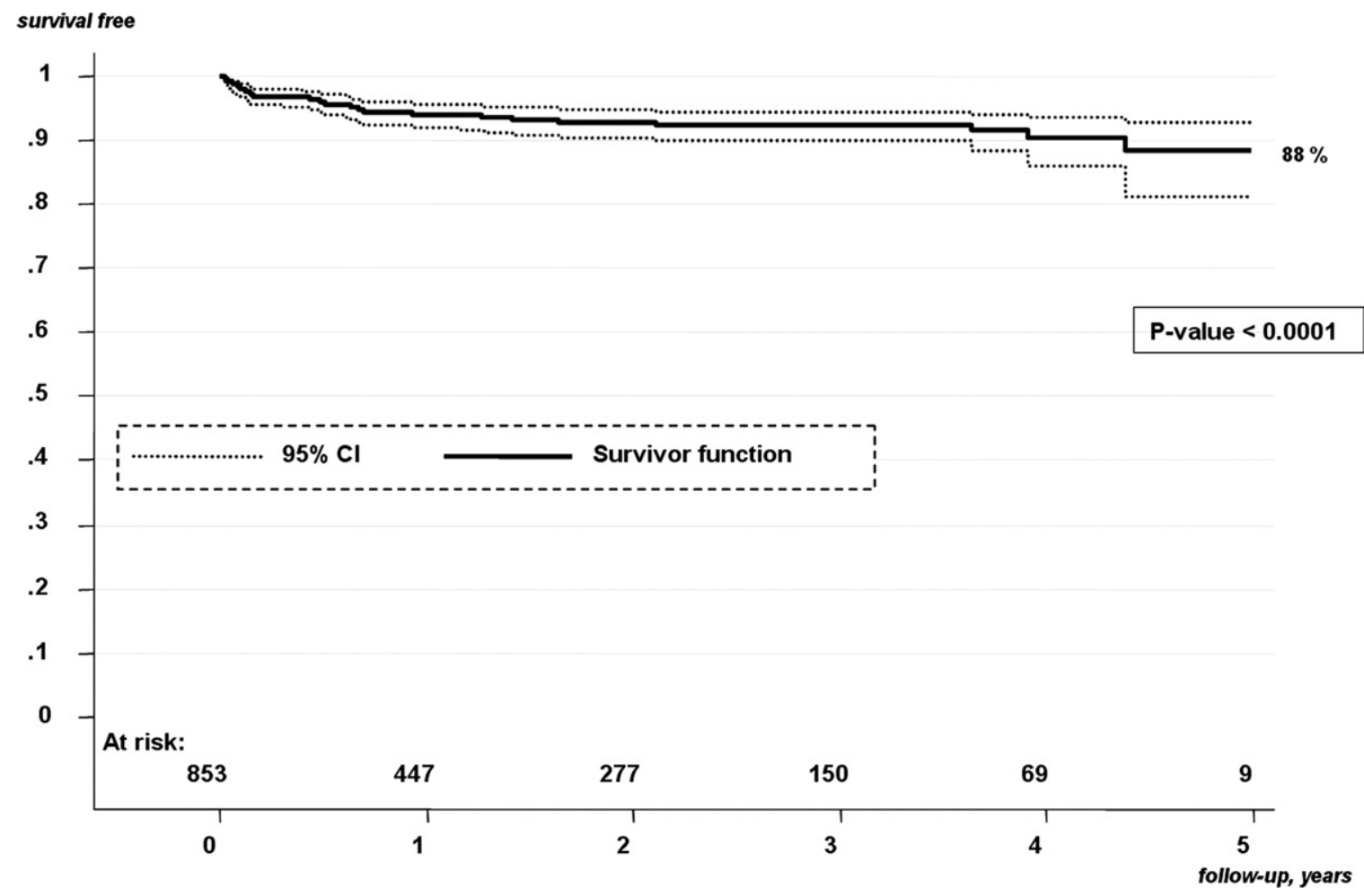

Figure 3. Overall freedom from adverse events.

later than the "proper time," this can still be carried out with a relatively low mortality risk.

In our experience the most represented group is the repair group (group 2), which shows excellent operative results in the early and midterm periods. This is generally true also for patients with single-ventricle anatomy who have undergone a physiologic correction by means of a Fontan repair and one-and-half-ventricle repair. However, our analysis demonstrates that single-ventricle diagnosis is still a considerable risk factor for mortality in the midterm (HR, 2.6; $P=.032$ ).

As reported by Srinathan and colleagues, ${ }^{10}$ it can be expected that the rate of first repair in adults will decrease as time goes by, whereas redo operations will represent the major portion of these procedures in the near future. About $30 \%$ of lesions undergoing repair in our series consisted of ASDs. It is surprising that such a large population of patients in our country are still undergoing surgical, rather than transcatheter, device closure. We could not identify a specific reason in this matter. However, despite presumed advantages of percutaneous closure in adults, ${ }^{11}$ our experience shows excellent early and midterm results, either in terms of mortality or clinical improvement, with no operative risk. In light of these results, we believe that especially in those patients with a history of transitory ischemic attack or neurological deficit caused by patency of foramen ovale, atrial septal aneurysm, or coagulation disorders, ASD surgical closure still plays an important role in avoiding the persistence of artificial conditions linked to device implantation. Longer follow-up is certainly needed in these patients to outline occurrence of arrhythmic events that are often causes of important morbidity in the long term. ${ }^{12}$

Group 1 (palliation) is the least represented group but presents with the worse results. It is predictable that palliative procedures will soon decrease in number because patients with cyanotic CHDs currently undergo repair in early infancy, with the aim of correcting or avoiding long-term cyanosis. A palliative procedure as an adult is still undertaken to improve temporarily the clinical status in patients with no chance for correction or other substitutive type of operation. A considerable rate of nonfatal complications has doomed the palliation group either in the postoperative course or in the follow-up period. This is predictable because we know that preoperative cyanosis is an important risk factor for early and midterm outcome of patients with adult CHD. ${ }^{3,10,13}$ The reason for this common finding is the existence of complex pathology, additional collateral pulmonary and mediastinal vascularization, bleeding disorders, and impaired cardiac function. ${ }^{14}$ Our statistical analysis confirms these data and underlines that when cyanosis is 
associated with NYHA functional class IV or diagnosis of transposition of the great arteries, the patient has an extremely high risk, accounting for HRs of 8.6 and 5.0, respectively.

As the number of patients who are treated for CHD in pediatric age is increasing around the world, a new emerging class is that of adult patients who are now facing the long-term effects of a residual congenital defect, the sequelae of the treatment, or both. Many of them do need a reoperation after primary repair. Limited knowledge exists on optimal timing for reoperations, perioperative risk factors, and long-term benefits. Surgical mortality in this subset of patients varies between $5.6 \%$ and $8.6 \% .^{10,13,15,16}$ In our experience early mortality of $7.6 \%$ is higher than for repair, and reoperation is associated with an HR of 2.3. In this group of patients, the intrinsic risk of intraoperative hemorrhage, postoperative hemorrhage, or both by redo sternotomy and management of adherences has to be taken into account. However, redo sternotomy has not been a cause of death in our experience. These patients are often in a more compromised preoperative clinical status, and as expected, they present with a high frequency of postoperative complications $\left(42.4 \%\right.$ in the series of Berdat and coworkers ${ }^{13}$ and $36.4 \%$ in ours). As also outlined by others, ${ }^{10,15,16}$ in our experience postoperative low cardiac output syndrome has been the main complication and cause of death in this subgroup. This finding confirms the current opinion that conditions that might have a negative effect on cardiac function, such as heart failure as an indication for reoperation or cyanosis, are identified as additional risk factors for postoperative death. ${ }^{10}$ In addition, we are inclined to think that some of these patients might have benefited from earlier intervention before irreversible myocardial deterioration was established, as proposed by some authors. ${ }^{17}$

Diller and associates ${ }^{18}$ have recently reported that exercise capacity is decreased in patients with adult CHD as in patients with chronic heart failure, even in mildly symptomatic patients. This retrospective analysis performed in 335 patients with heterogeneous CHD points out the concept that patients with adult CHD represent a very complex group of patients and that even when asymptomatic they hide a less than normal cardiac situation. For this reason, we think that if surgical intervention is meant to be of some help for these patients, 2 things have to be kept in mind: (1) surgical intervention should be performed before it is too late, and therefore surgical indication should be precocious, and (2) it is legitimate to think that postoperative intensive care knowledge in this field needs to be improved to be ready to face this increasing group of demanding patients. A devoted team of caregivers have to be well trained to treat these complex patients appropriately. This complex population is estimated to grow 5\% per year. ${ }^{19}$ Thus it is imperative that the medical community soon structures a func- tional care network for adult CHD based on clinicians and surgeons with an adequate training and knowledge of CHD and physiology, together with knowledge of the problems of adult patients. As described by some authors, ${ }^{20}$ care should be specialized in devoted hospital units where a complete team of cardiologists, congenital cardiac surgeons, a heart and heart-lung transplant team, intensive care specialists, anesthesiologists, and also endocrinology, gynecology, and psychiatry specialists should be involved. In addition, the primary caregiver should be trained in following these patients so as to ensure a close contact with patients. ${ }^{20}$

In conclusion, the outcome of the surgical treatment of CHD in adults is still uncertain, and a new field is to be discovered. Our analysis predicts good midterm postoperative outcomes that allow surgeons to be relatively optimistic in proposing surgical treatment in this difficult category of patients. Closer follow-up and learning the optimal surgical timing is expected to maintain good results in the long term.

\section{References}

1. Webb GD. Care of adults with congenital heart disease. A challenge for the new millennium. Thorac Cardiovasc Surg. 2001;49:30-4.

2. Chessa M, Cullen S, Deanfield J, et al. The care of adult patients with congenital heart defects: a new challenge. Ital Heart J. 2004;5:178-82.

3. Stellin G, Vida VL, Padalino MA, Rizzoli G. Surgical outcome for congenital heart malformations in the adult age. A multicentric European study. Semin Thorac Cardiovasc Surg Pediatr Card Surg Annu. 2004; 7:95-101.

4. Somerville J. Management of adult with congenital heart disease. An emerging increasing problem. Ann Rev Med. 1997;48:283-93.

5. Warnes CA, Liberthson R, Danielson GK, et al. Task force 1: the changing profile of congenital heart disease in adult life. J Am Coll Cardiol. 2001;37:1170-5.

6. Williams WG, Webb GD. The emerging population with congenital heart disease. Semin Thorac Cardiovasc Surg Pediatr Card Surg Annu. 2000;3:227-33

7. Wren C, O'Sullivan JJ. Survival with congenital heart disease and need for follow up in adult life. Heart. 2001;85:438-43.

8. Daliento L, Mazzotti E, Mongillo E, Rotundo M, Dalla Volta S. Life expectancy and quality of life in adult patients with congenital heart disease. Ital Heart J. 2002;3:339-47.

9. Warnes CA. The adult with congenital heart disease. Born to be bad? J Am Coll Cardiol. 2005;46:1-8.

10. Srinathan SK, Bonser RS, Sethia B, Thorne SA, Brawn WJ, Barron DJ. Changing practice of cardiac surgery in adult patients with congenital heart disease. Heart. 2004;91:207-12

11. Butera G, Carminati M, Chessa M, et al. Percutaneous versus surgical closure of secundum atrial septal defect: comparison of early results and complications. Am Heart J. 2006;151:228-34.

12. Murphy JG, Gersh BJ, McGoon MD, et al. Long term outcome after surgical repair of isolated atrial defect. Follow up at 27 to 32 years. N Engl J Med. 1990;333:469-73.

13. Berdat PA, Immer F, Pfammatter JP, Carrel T. Reoperations in adults with congenital heart disease: analysis of outcome. Int J Cardiol. 2004;93:239-45.

14. Dore A, Luke Glancy D, Stone S, Menasche VD, Somerville J. Cardiac surgery for grown up congenital heart patients: survey of 307 consecutive operations from 1991 to 1994. Am J Cardiol. 1997;80: 906-13.

15. Isomura $\mathrm{T}$, Hisatomi $\mathrm{K}$, Andoh $\mathrm{F}$, et al. Reoperation following total repair of congenital heart disease. Jpn Circ J. 1991;55:453-8.

16. Geissler HJ, Sudkamp M, Nowak J, de Vivie ER. Congenital heart defects in adolescence and adulthood: fatalities and morbidity in primary and reoperation. Z Kardiol. 1996;85:782-9. 
17. Therrien J, Siu SC, McLaughlin PR, Liu PP, Williams WG, Webb GD. Pulmonary valve replacement in adults late after repair of tetralogy of Fallot: are we operating too late? J Am Coll Cardiol. 2000;36:1670-5.

18. Diller GP, Dimopoulos K, Okonko D, et al. Exercise intolerance in adult congenital heart disease. Comparative severity, correlates and prognostic implications. Circulation. 2005;112:828-35.

19. Brickner ME, Hillis LD, Lange RA. Congenital heart disease in adults. First of two parts. $N$ Engl J Med. 2000; 342: 256-263.

20. Therrien J, Gatzoulis M, Graham T, et al. Canadian Cardiovascular Society Consensus Conference 2001 update: recommendations for the management of adults with congenital heart disease-part II. Can J Cardiol. 2001;17:1029-50.

\section{Discussion}

Dr Hillel Laks (Los Angeles, Calif). Thank you, Dr Jonas, Dr Kron. I would like to thank the association for the invitation to discuss this article and Dr Padalino for sharing his manuscript and information with us.

I think this is an important article because it allows us to focus a little bit on the issue of the place of adult CHD in the training of surgeons, the qualification of centers and surgeons who do this kind of operation, and the importance of analyzing outcomes in multicenter studies, because for most centers, the available numbers are not enough to really analyze them. Dr Padalino and his group from Italy have shown that in 7 centers approximately 34 cases were done per year per center, but there are obviously some who had much larger volumes than others. I wanted to ask: what were the types of centers, how many were children's hospitals, how many were general hospitals operating on children and adults, and how many were pure adult hospitals? In the Euro Cardio Survey, they found that of 71 centers that participated, 48 were considered referral centers, and of those 48 , according to the Euro Survey Committee, only one fifth were considered as qualified to do adult congenital heart surgery. I think that associations and the population of surgeons needs to consider what is required for the training of a surgeon to do adult $\mathrm{CHD}$ and what is required for a center.

It is not too dissimilar to the situation with transplantation, where it is now recognized that a center requires not just a surgeon who can do the operation but a full team of specialists, nurses, and anesthesiologists and infrastructure to take care of very complex patients.

The numbers of these patients is increasing as the survivals have increased, and in Italy the number is estimated to be about 80,000 patients. In the United Kingdom, with about the same population, it is estimated that there were about 145,000 patients in 2000 , and it is estimated that by the year 2010 there will be 185,000 patients with adult CHD. In the United States the estimate is 800,000 patients, recognizing that of live births with $\mathrm{CHD}$, about 1.5 per 1000 are simple and 4.5 per 1000 complex. And as our results improve for the complex patients, more of them are surviving into adulthood and presenting us with the kind of problems that you describe. At UCLA we have done approximately 55 on average over the last 5 years of adult CHDs per year, and virtually none of them nowadays, with catheter techniques, are ASDs. Most of them are more complex. About $5 \%$ of our 1500 transplantations are for patients with CHD. Although in a center that is doing 1000 or 900 cases a year this is not a very large percentage of the volume, similar to transplantation, it does require a concentration of resources.

My other question for you is in view of the prevalence of the arrhythmias, both as postoperative complications and late morbid- ity. Are the centers doing prophylactic maze procedures and inserting AICDs to affect this early and late morbidity and mortality?

My last question concerns the numbers of patients referred for heart transplantations, double-lung and heart-lung transplantations, and how many of these centers are also transplantation centers?

I would like to congratulate you for a very excellent presentation and give my thanks to the association for allowing me to discuss this.

Dr Padalino. Thanks, Dr Laks, for your nice statement. Well, first of all, I would like to underline that we decided to start this study to evaluate the situation of resources in our country and to face the growing entity of this type of population, which is a very difficult one. Despite most of our patients being in NYHA class I or II, we expect these patients' conditions to become more complicated in the future.

As far as the centers that were involved, there are actually 7 centers that joined the study, and 50\% of them are pediatric centers. Therefore they just deal with patients in the pediatric age, whereas the remaining centers have also an adult service. The limitation in getting the data also depends on this difference among these centers.

The same is applicable to your other question regarding the transplantation service; a few centers have transplantation services and facilities or they have government assignments to do transplantation surgery. Therefore diagnoses and patients that we selected might not reflect the real situation in our country.

As far as onset of arrhythmias and arrhythmia procedures, the main trend is to treat these patients with an ablation procedure, cryoablation or radiofrequency ablation, when it is indicated. However, indication for surgery depends on the EP cardiology service characteristics of each center.

As far as the heart-lung programs, heart-lung programs are not common, and only a few of our referring centers are involved in a heart-lung program. Thus they differ in the attitude they have when they face this kind of problem. I believe that a minority of our centers are involved in heart-lung programs.

Dr Richard Jonas (Washington, DC). Dr. Padalino, Dr Laks has pointed out the importance of having a team that is specialized and familiar with complex congenital heart problems, and many such teams are based in a children's hospital. What sort of problems do you foresee in having middle-aged and elderly patients with congenital heart problems managed in a children's hospital, and what is the best way to deal with those problems?

Dr Padalino. I believe that treating an adult patient in a pediatric service can provoke a sort of inadequate treatment of adult patients, who also present with a lot of other problems - not only cardiologic problems, but frequently also psychological problems, internal medicine problems, and other things. Therefore, what we believe is that pediatric cardiologists and adult cardiologists should work together in trying to finalize the diagnosis and that the pediatric cardiac surgeon has to be involved in the treatment of this kind of lesion because the pediatric cardiac surgeon is the one who is in charge of the congenital heart lesion and therefore the one who knows better the lesion and also the physiology.

We believe also that more adult specialists have to be involved in the care of these patients. We think that adult congenital cardiac patient services should be a multispecialist team, in which cardiologists, congenital cardiac surgeons, intensive care unit specialists, EP cardiologists, imaging specialists, and also internal medicine, gynecology, and psychiatrics divisions have to be included. 


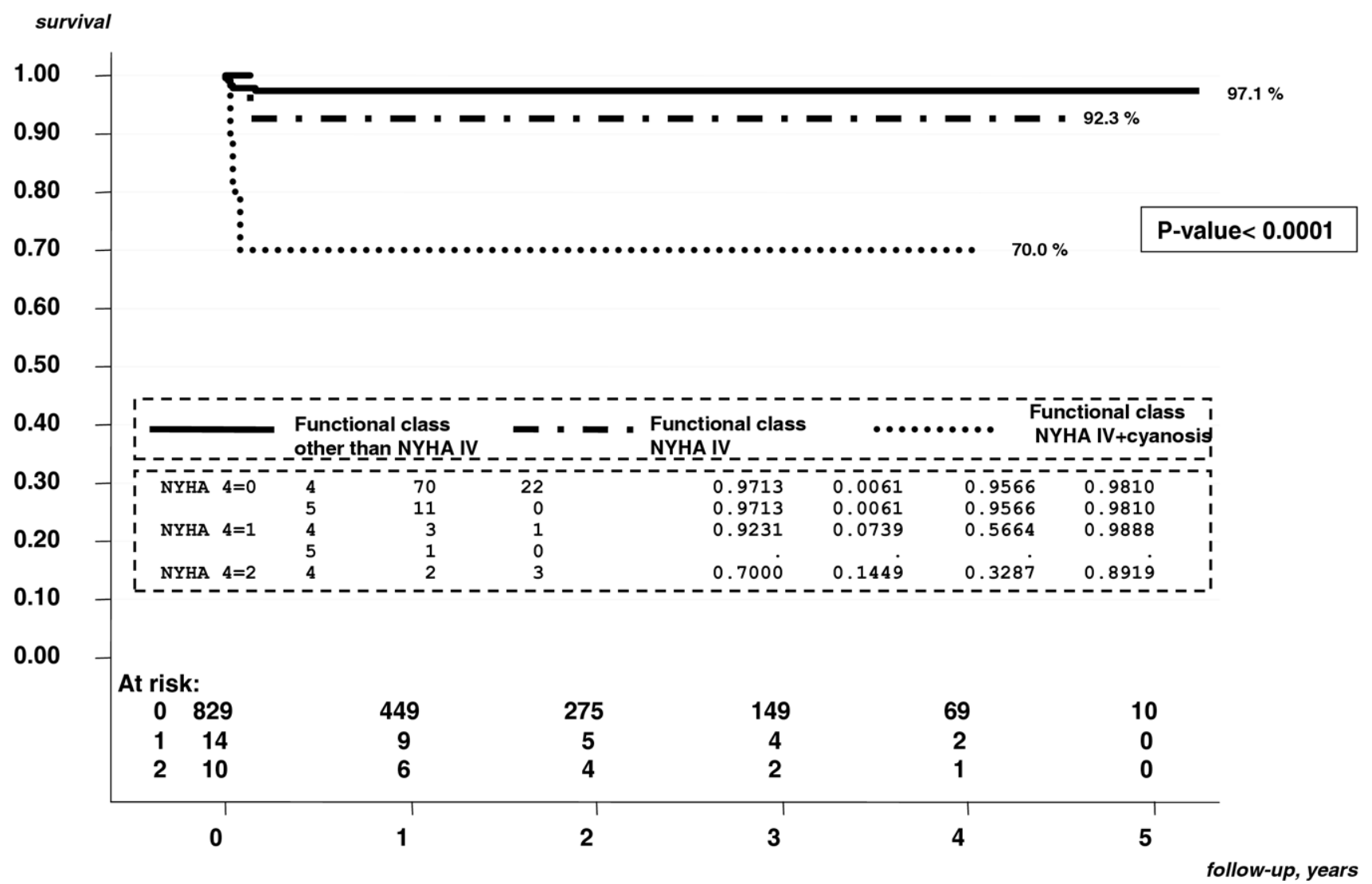

Figure E1. Survival estimates, preoperative New York Heart Association (NYHA) class IV with or without cyanosis. 


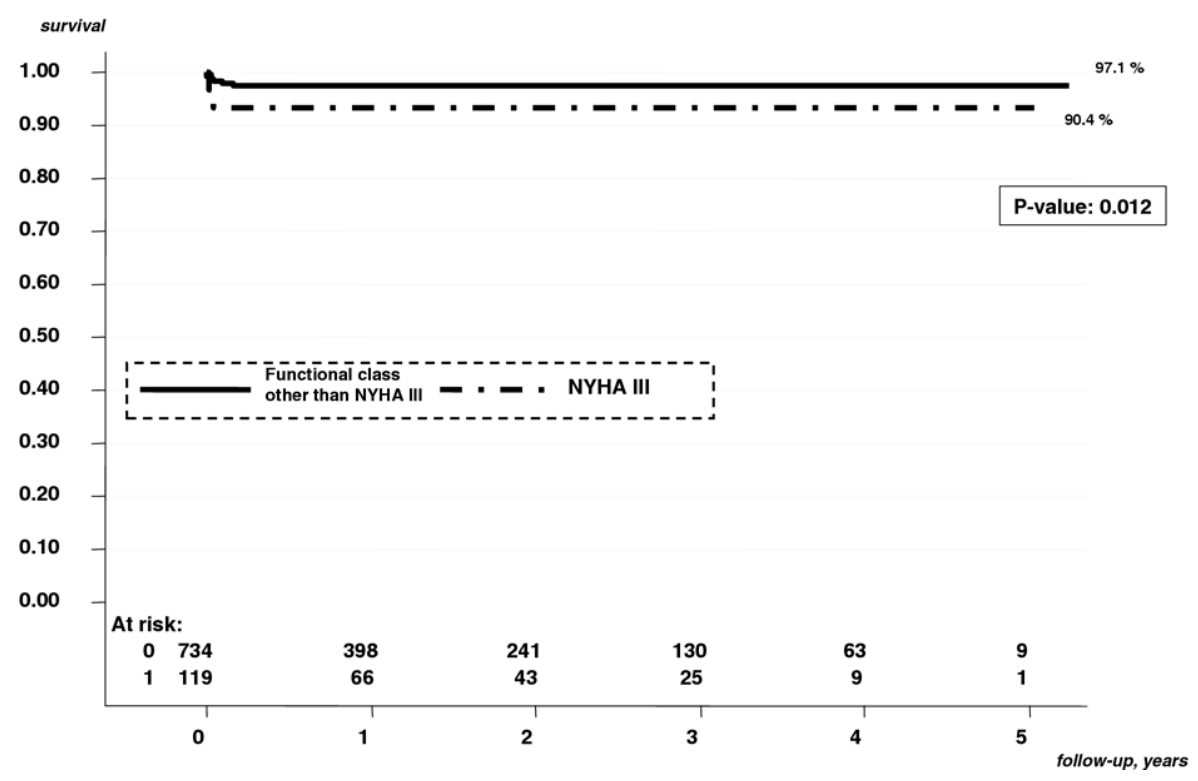

Figure E2. Kaplan-Meier survival estimates by preoperative New York Heart Association (NYHA) class III.

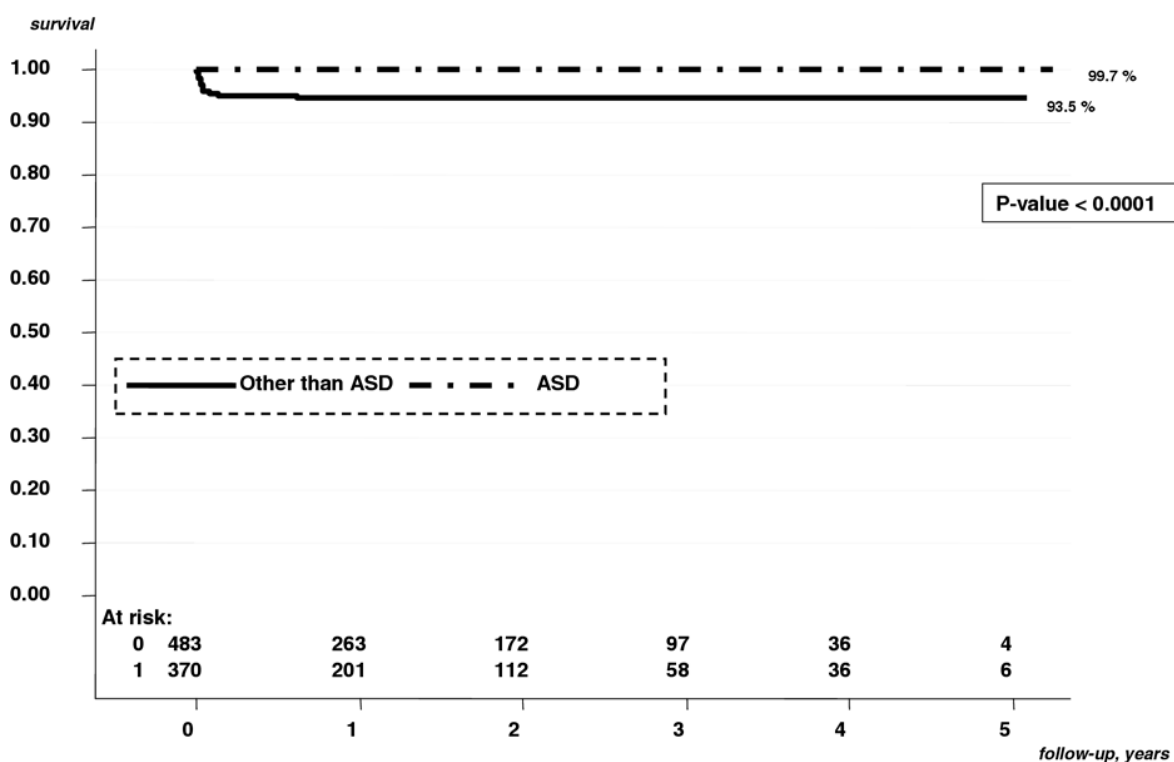

Figure E3. Kaplan-Meier survival estimates by diagnosis of atrial septal defect (ASD). 


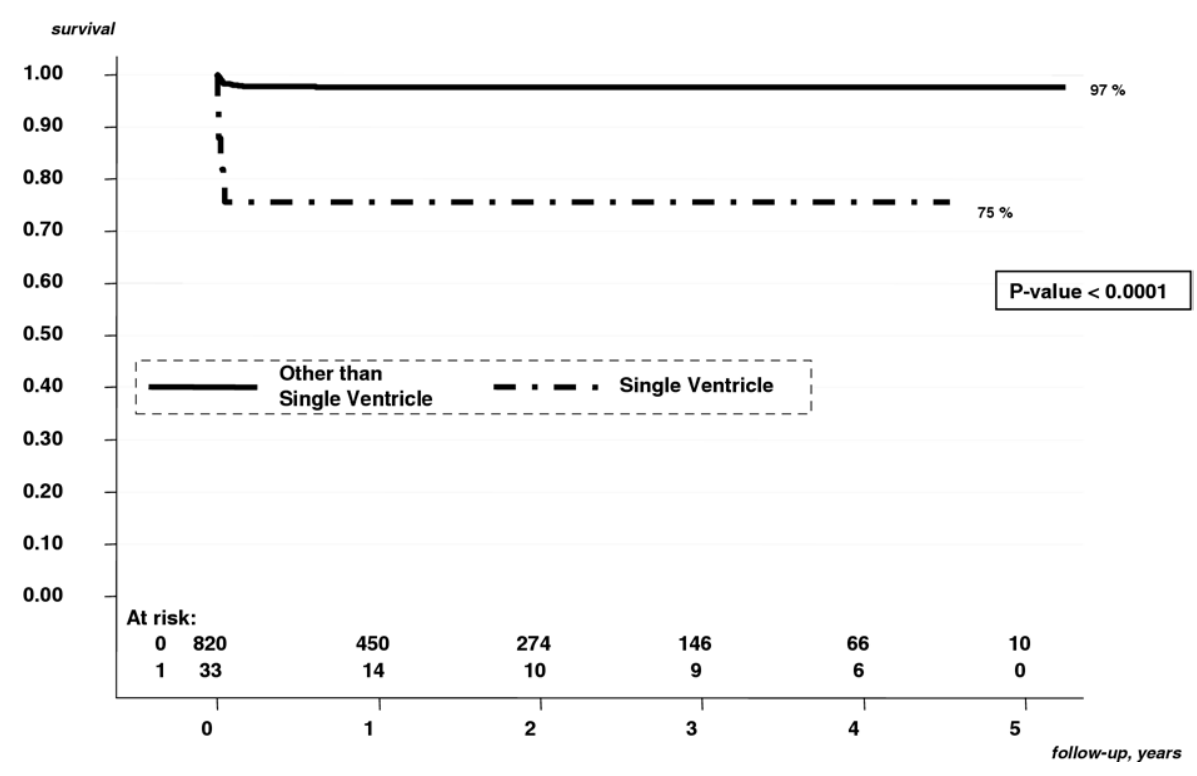

Figure E4. Kaplan-Meier survival estimates by single-ventricle diagnosis.

\begin{tabular}{|c|c|c|c|c|c|c|}
\hline \multicolumn{7}{|c|}{ At risk: } \\
\hline 0 & 820 & 450 & 274 & 146 & 66 & 10 \\
\hline 1 & 33 & 14 & 10 & 9 & 6 & 0 \\
\hline & ${ }_{0}^{1}$ & 1 & $2^{1}$ & $3^{1}$ & 4 & 5 \\
\hline
\end{tabular}

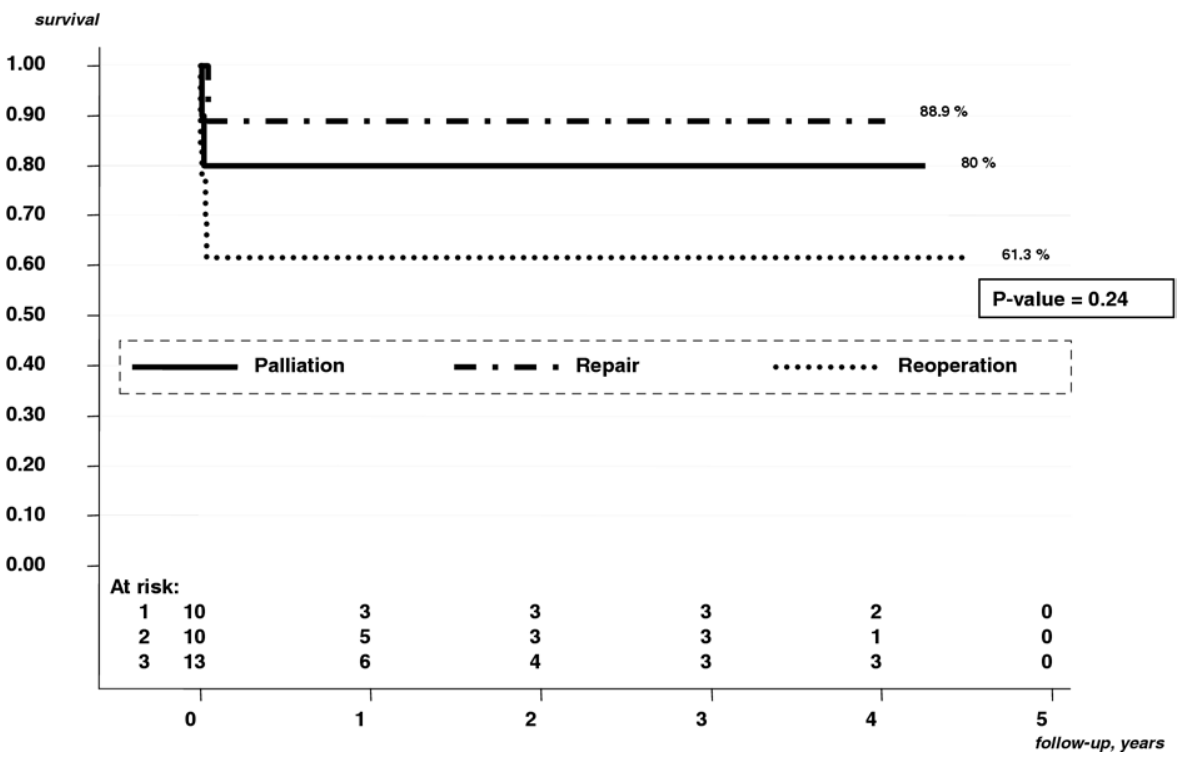

Figure E5. Single ventricle by surgical category. 


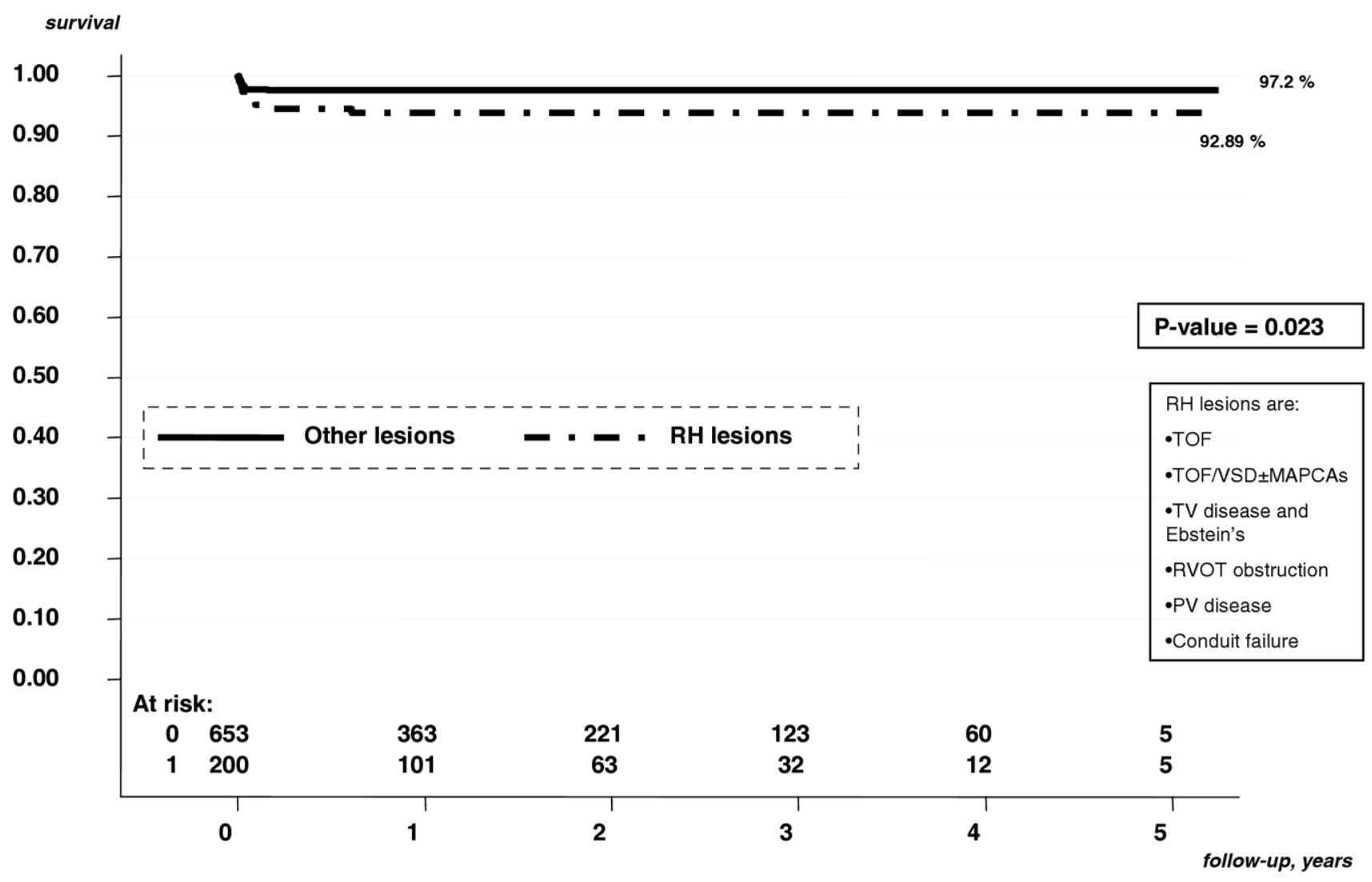

Figure E6. Right heart (RH) lesions. TOF, Tetralogy of Fallot; VSD, ventricular septal defect; MAPCAs, Major aortopulmonary collateral arteries; TV, tricuspid valve; RVOT, right ventricular outflow tract; PV, pulmonary valve. 


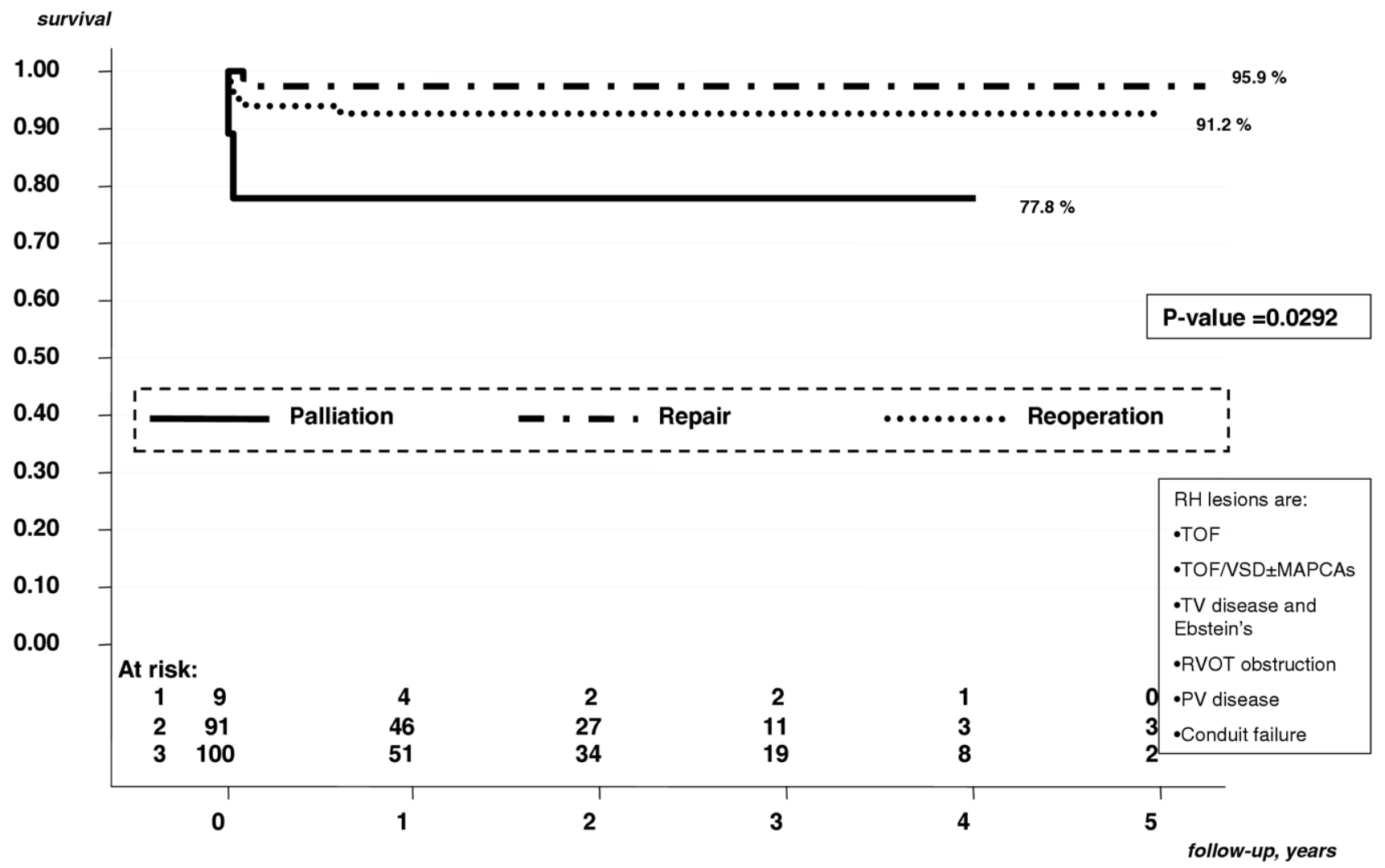

Figure E7. Right heart lesions by surgical category. TOF, Tetralogy of Fallot; VSD, ventricular septal defect; MAPCA, major aortopulmonary collateral arteries; TV, tricuspid valve; RVOT, right ventricular outflow tract; PV, pulmonary valve. 


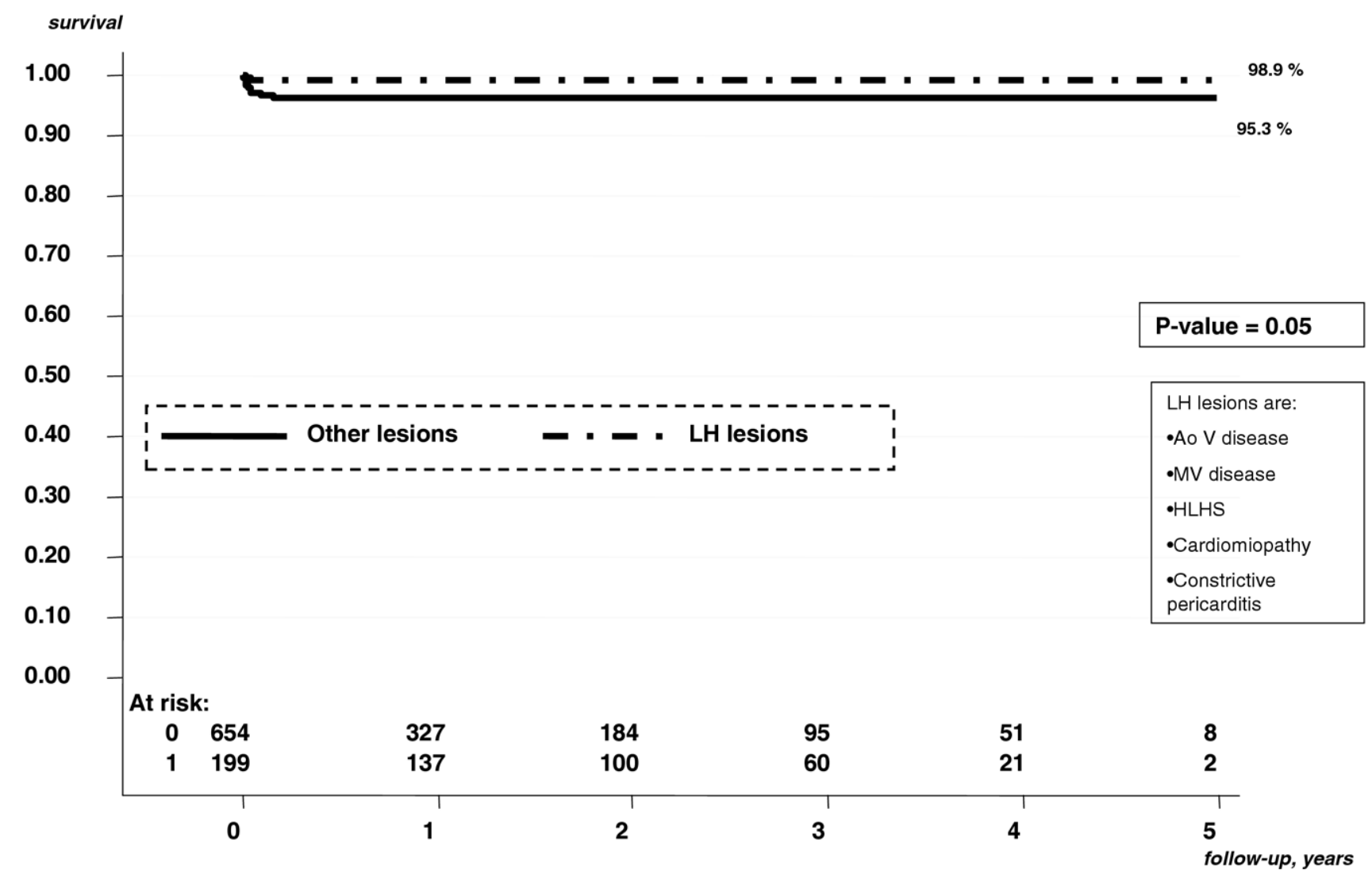

Figure E8. Left heart (LH) lesions. AoV, Aortic valve; MV, mitral valve; HLHS, hypoplastic left heart syndrome. 


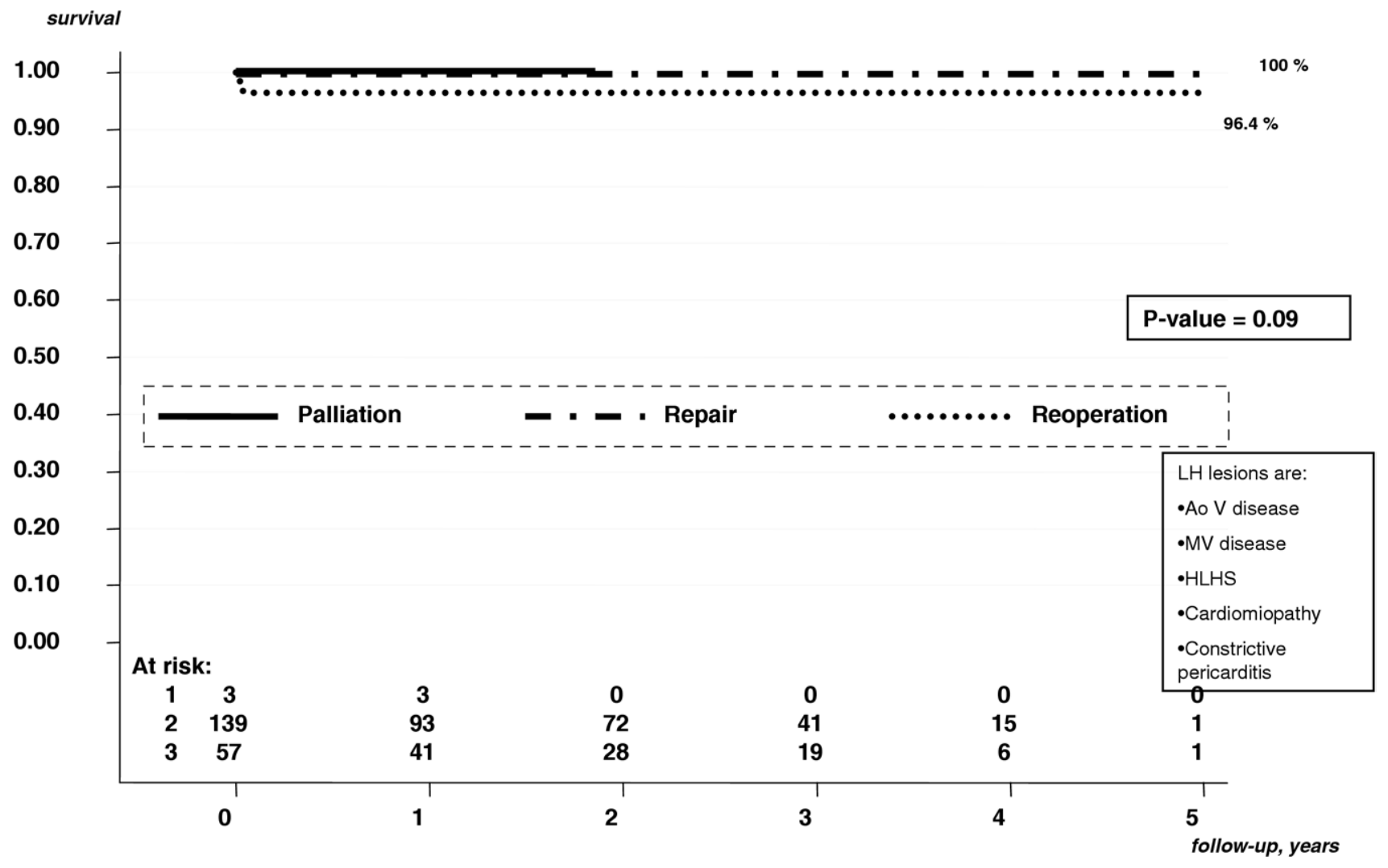

Figure E9. Left heart lesions by category. AoV, Aortic valve; MV, mitral valve; HLHS, hypoplastic left heart syndrome. 


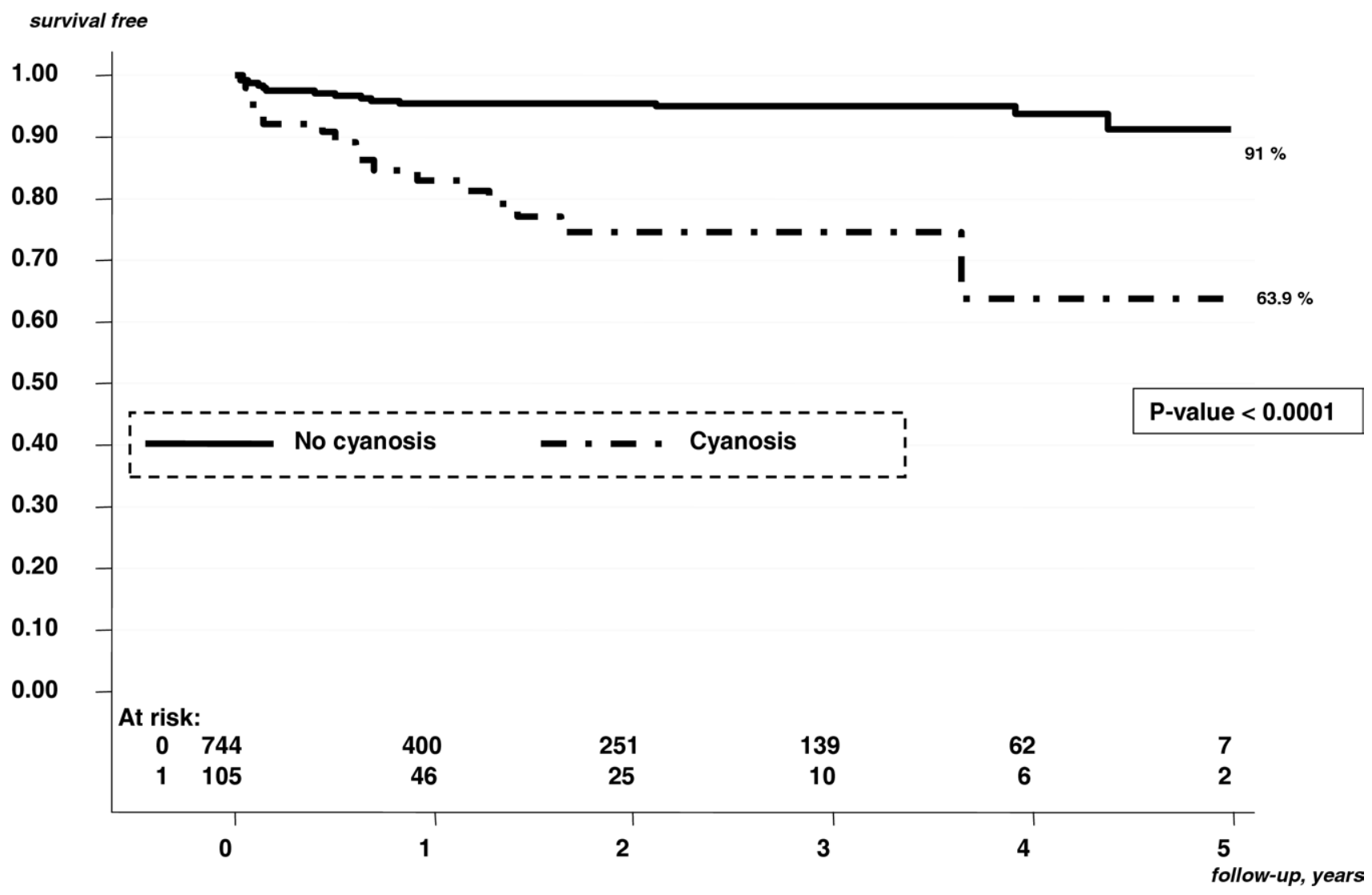

Figure E10. Freedom from adverse events: cyanotic versus noncyanotic.

TABLE E1. A. Anatomic diagnoses

\begin{tabular}{lrr}
\hline Diagnosis & No. & $\%$ \\
\hline Atrial septal defect & 321 & 26.84 \\
Aortic regurgitation & 98 & 8.19 \\
Tetralogy of Fallot & 73 & 6.10 \\
Partial anomalous pulmonary venous & 70 & 5.85 \\
$\quad$ connection & & \\
Tricuspid valve disease & 65 & 5.43 \\
Ventricular septal defect & 60 & 5.02 \\
Atrioventricular septal defect & 54 & 4.52 \\
Subaortic stenosis & 43 & 3.60 \\
Arrhythmia & 41 & 3.43 \\
Functional single ventricle & 34 & 2.84 \\
Aortic coarctation & 25 & 2.09 \\
Pulmonary valve regurgitation & 20 & 1.67 \\
Pulmonary atresia & 18 & 1.51 \\
Pulmonary stenosis & 11 & 0.92 \\
Physiologically corrected & 9 & 0.75 \\
$\quad$ transposition of the great arteries & & \\
Other & 265 & 21.24 \\
\hline
\end{tabular}

TABLE E1. B. “Leading to surgical intervention” diagnoses Leading to surgical intervention diagnosis No.

Atrial septal defect

\begin{tabular}{ccc} 
& No. & $\%$ \\
\hline \multirow{3}{*}{ nous } & 307 & 28.8 \\
99 & 9.29 \\
& 65 & 6.10
\end{tabular}

Aortic regurgitation

(20)

onnection

Aortic stenosis

Tricuspid valve disease

5.91

Ventricular septal defect

Atrioventricular septal defect

Arrhythmia

4.39

Tetralogy of Fallot

Pulmonary artery stenosis

Conduit failure

2.91

Mitral valve regurgitation $\quad 31 \quad 2.91$

$\begin{array}{lll}\text { Pulmonary stenosis } & 29 & 2.72\end{array}$

$\begin{array}{lll}\text { Aortic aneurysm } & 27 & 2.53\end{array}$

Functional single ventricle-Fontan $\quad 26 \quad 2.44$

Aortic coarctation $\quad 24 \quad 2.25$

Pulmonary atresia $\quad 6 \quad 0.76$

$\begin{array}{lll}\text { Physiologically corrected } & 2 & 0.20\end{array}$

transposition of the great arteries

Other

81

7.60 
TABLE E2. Early outcome per group

\begin{tabular}{|c|c|c|c|c|}
\hline & $\begin{array}{c}\text { Palliation } \\
\text { (18 patients) }\end{array}$ & $\begin{array}{c}\text { Repair } \\
\text { (628 patients) }\end{array}$ & $\begin{array}{l}\text { Reoperation } \\
\text { (210 patients) }\end{array}$ & $\begin{array}{c}\text { Total } \\
\text { (856 patients) }\end{array}$ \\
\hline Early death & $3(16.6 \%)$ & $8(1.27 \%)$ & $16(7.6 \%)$ & $27(3.1 \%)$ \\
\hline Early death, LCO Sdr & 1 & 3 & 9 & 13 \\
\hline Major postoperative complications & 13 & 138 & 81 & 247 \\
\hline Arrhythmias & 1 & 53 & 10 & 64 \\
\hline LCO Sdr & 5 & 10 & 13 & 28 \\
\hline Bleeding & 0 & 13 & 11 & 24 \\
\hline Sternum left opened & 0 & 1 & 6 & 7 \\
\hline Unplanned reoperation during same admission & 1 & 8 & 1 & 10 \\
\hline Postoperative VAD/ECMO & 1 & 2 & 4 & 7 \\
\hline Postoperative AV block requiring permanent PM & 0 & 7 & 3 & 10 \\
\hline Prolonged mechanical ventilation & 1 & 6 & 10 & 17 \\
\hline Postoperative cardiac arrest & 1 & 2 & 1 & 4 \\
\hline Acute renal failure requiring temporary dialysis & 1 & 0 & 0 & 1 \\
\hline Pleural effusion requiring drainage & 2 & 8 & 9 & 19 \\
\hline Pneumothorax & 0 & 10 & 0 & 10 \\
\hline Other minor & 15 & 18 & 13 & 46 \\
\hline ICU stay (mean, d) & 5.2 & 1.8 & 3.5 & 2.3 \\
\hline
\end{tabular}

LCO Sdr, Low cardiac output syndrome; $V A D$, ventricular assist device; ECMO, extracorporeal membrane oxygenator; $A V$, atrioventricular; $P M$, pacemaker; $I C U$, intensive care unit.

TABLE E3. Preoperative and postoperative electrocardiographic findings

\begin{tabular}{lcc}
\hline ECG rhythm & Preoperative (\%) & Postoperative (\%) \\
\hline Sinus & 83 & 90.5 \\
Atrial fibrillation & 6.4 & 2.5 \\
A-V block, third degree & 1.1 & $0.8^{*}$ \\
Atrial flutter & 0.7 & 0.2 \\
No available data & 8.8 & 6.0 \\
\hline
\end{tabular}

$E C G$, Electrocardiographic; $A-V$, atrioventricular. ${ }^{*}$ Three patients affected died at the time of the operation.

TABLE E4. Late outcome per group

\begin{tabular}{lccc}
\hline Adverse events & $\begin{array}{c}\text { Palliation } \\
\text { (17 survivors) }\end{array}$ & $\begin{array}{c}\text { Repair } \\
\text { (620 survivors) }\end{array}$ & $\begin{array}{c}\text { Reoperation } \\
\text { (194 survivors) }\end{array}$ \\
\hline Late death, cardiac & $/$ & 3 & 1 \\
Late death, noncardiac & $/$ & 0 & 1 \\
Reoperation & 2 & 4 & 3 \\
$\begin{array}{l}\text { Interventional } \\
\text { Other (eg, arrhythmias }\end{array}$ & 1 & 2 & 2 \\
$\quad$ and pleural & 5 & 21 & 3 \\
$\quad$ effusions) & & & \\
Total & 8 & 30 & 10 \\
\hline
\end{tabular}

